This is an Accepted Manuscript published in the Springer Communications in Computer and Information Science book series (CCIS, volume 1351). Please cite as:

Winter M. (2021) Display Placement and Design: Impact on Engagement with Social Object Labels in a Gallery Environment. In: Escalona M.J., Ramirez A.J., Silva H.P., Constantine L., Helfert M., Holzinger A. (eds) Computer-Human Interaction Research and Applications. CHIRA 2018, CHIRA 2019. Communications in Computer and Information Science, vol 1351. Springer, Cham. https://doi.org/10.1007/978-3-030-67108-2_1.

First Online: 22 January 2021 | DOI https://doi.org/10.1007/978-3-030-67108-2_1 | Print ISBN 978-3-030-67107-5 | Online ISBN 978-3-030-67108-2

\title{
Display Placement and Design: Impact on Engagement with Social Object Labels in a Gallery Environment
}

\author{
Marcus Winter [0000-0001-6603-325X] \\ School of Computing, Engineering and Mathematics, University of Brighton, Brighton, UK \\ marcus.winter@brighton.ac.uk
}

\begin{abstract}
Considering placement and content design as key factors determining attention and engagement with interactive public displays, this paper reports on an empirical study investigating attention and engagement with social object labels as a particular instance of that display class in a museum context. It describes a field trial in a live gallery environment evaluating a range of display placements and designs. The study suggests that (i) placement has a major impact on attention and engagement; (ii) the attention potential of display placements can be quantified to predict attention and engagement rates; (iii) interaction- and information design only have a minor impact on some engagement metrics. The findings help to better understand how placement and design influence attention and engagement with public displays and underline the need for further research exploring these aspects in other contexts.
\end{abstract}

Keywords: HCI; attention; engagement; interaction; public displays; pervasive displays; social object labels; interpretation; participation; museum.

\section{Introduction}

Interactive public displays have been researched extensively over the past two decades, having their own series of international symposia since 2012 [22]. One of their many promising application areas is visitor engagement in museums. Besides providing guidance in concourse areas and curated information in galleries, interactive public displays also support participation, with display content created by visitors themselves rather than the institution. Social interpretation, where visitors share their own thoughts about exhibits and exhibition themes, is a particularly interesting application in this context, promising to contextualize and democratize museum interpretation [36, 48], enrich exhibitions and make them more inclusive [31], and support museums' higher-level educational goals by facilitating their transition from transfer learning to social-constructivist learning approaches $[14,19]$. One research effort aiming to support social interpretation in museums are social object labels (SOLs) [51, 52], small interactive e-ink displays enabling visitors to add their own thoughts and interpretations to exhibits (Fig. 1). They give visitors a voice and a platform to relate exhibition themes to their own personal experiences and complement the museum's official interpretation on traditional object labels with socially constructed interpretations on SOLs. 


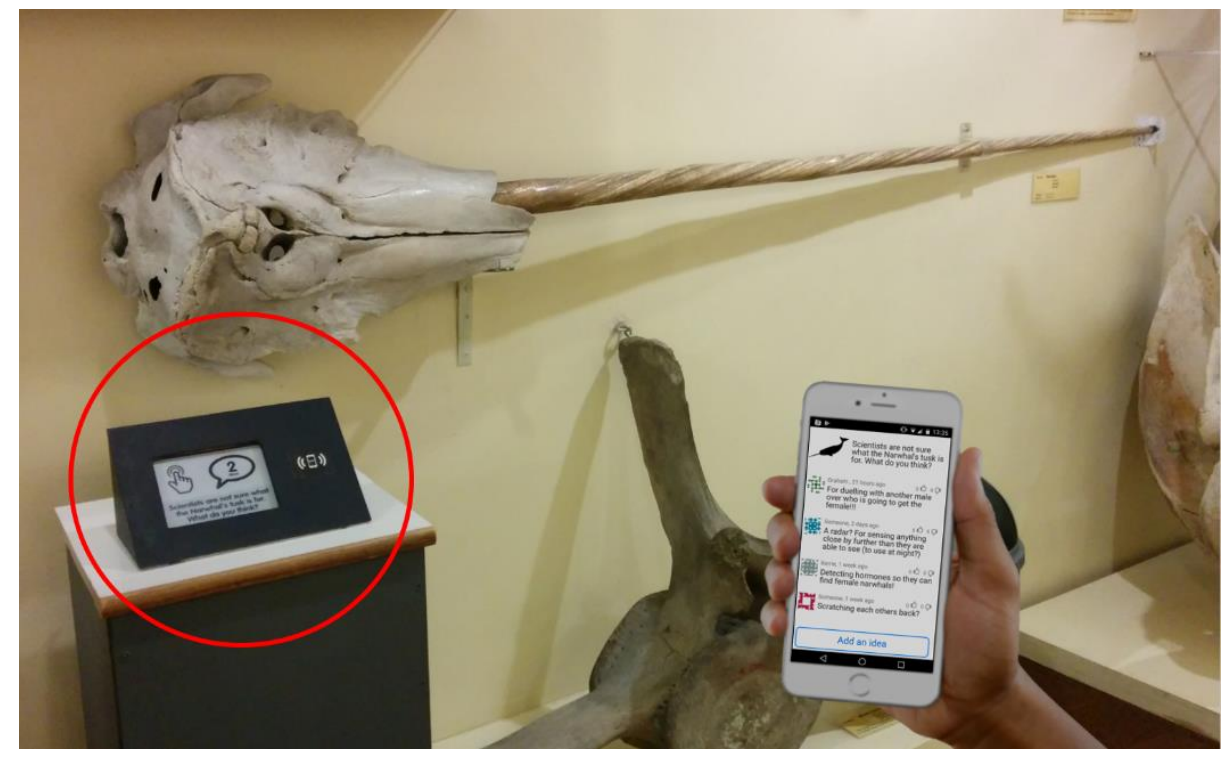

Fig. 1. SOL (circled) and related mobile application at the Booth Museum in Brighton, asking visitors to contribute their ideas on why narwhals have their particular tusk.

As curated spaces with an educational agenda and their own rules and social norms, museums are complex environments with specific requirements and constraints for technology deployed in the gallery space. Of particular concern in this context is to carefully manage an economy of attention [45] by ensuring that technology is used "in ways that do not distract from the exhibition themes" [30:601) and "preserve the primacy of the object and aesthetic encounter" [46:3]. A critical design tension for SOLs is therefore to be inconspicuous enough to not divert visitors' attention from exhibits while being conspicuous enough to be noticed and to encourage engagement.

With placement and design identified as key factors in the HCI literature discussing attention and engagement with public displays, this paper reports on a field study assessing the impact of these two aspects on visitors' attention and engagement with SOLs in a live gallery environment. Its key contributions are to provide empirical evidence showing with high ecological validity that (i) display placement has a significant impact on attention and engagement; (ii) the attention potential of placements can be quantified to predict attention and engagement rates; (iii) variations in the interaction- and information design of SOLs only had a minor influence on some engagement metrics. The findings underline the need to better understand how placement-related factors impact on attention and engagement and advance the development of methods to quantify the attention potential of placements, which can help to inform the design, deployment and evaluation of interactive public displays.

The following sections review related work on attention and engagement with public displays, describe a field trial of SOLs at Science Gallery Dublin and discuss its findings with regard to the impact of display placement and design on visitors' attention and engagement. The paper concludes by discussing limitations of the study and sketching 
out future work towards a better understanding of effective placement and design of interactive public displays.

\section{$2 \quad$ Related work}

Attention as "the process that brings a stimulus into consciousness" (25:25) is typically seen as a pre-condition for engagement, described as both the act of making initial contact and the state of being occupied with the object of attention [35]. The terms are widely discussed in the $\mathrm{HCI}$ literature, in particular in ubiquitous computing contexts where attention is often fragmented as multiple activities and stimuli vie for users' finite cognitive resources.

With regard to SOLs and their particular design tensions in museum environments, two of the most relevant research areas are ambient displays and interactive public displays. While the former is strongly influenced by the vision of calm computing [50] and seeks to minimize users' cognitive load of taking in information by blending into the environment and targeting their peripheral attention [27, 28], the latter is not constrained by such concerns. Important questions in public display research are simply how to attract the attention of audiences and, for interactive displays, how to communicate interactivity and encourage engagement.

In addition to these HCI perspectives, the field of museum studies offers highly relevant insights into attention and engagement in gallery environments. Besides providing detailed guidelines on label design, which can inform the information design of SOLs, this field also offers deep insights how visitors experience museums and how their attention and engagement is influenced by a wide range of factors.

\subsection{Attention and ambient displays}

Research into ambient information systems offers various models to conceptualize and structure attention into different states or realms. These include among others peripheral and focused attention [29]; primary, secondary and tertiary realms of attention [18]; pre-attention, in-attention, divided attention and focused attention [27]. Common to all these notions is that attention can be voluntary or involuntary [25], and that displays should address multiple forms of attention and support transitions between them. The latter typically involves targeting peripheral attention by default and escalating to focused attention and interaction when an exception occurs.

\subsection{Attention and engagement models for public displays}

Engagement models for public displays can be broadly classified into ad-hoc models, describing how displays react to users, and observational models, describing how users engage with displays [32]. Ad-hoc models typically employ proxemic interaction concepts $[16,47]$ to support specific stages in observational engagement models such as attracting attention and communicating interactivity. 
Perhaps the best known observational model of engagement with interactive public displays is the audience funnel [32], which identifies six stages including passing by; viewing and reacting; subtle interaction; direct interaction; multiple interaction; and follow-up action. An earlier observational model [9] describes three levels of engagement, including peripheral awareness; focal awareness; and direct interaction. That work also discusses how displays can encourage users to transition between stages and increase their engagement. A model focusing in particular on engagement with public display games [15] defines seven interaction states including enter; glance; decode; observe; input; feedback; and result. The authors also discuss relevant design aspects to support users in each of these states. Finally, a model for engagement with public access systems [23] identifies four stages including attraction; learning; engagement; and disengagement. Guidelines how displays can support users in each of these stages are discussed in [24].

The majority of recommendations around attention and engagement with public displays relate to design aspects such as content type and representation $[3,8,44]$, information design [3, 26, 44], calls to action [24], and learnability and usability [24, 26, 34]. However, some recommendations refer to placement aspects such as the height at which displays are installed $[11,20]$, the available space around them for interaction to take place $[9,24]$, the direction of people's movement within a space [20], the vicinity of other eye-catching objects [20] and, for multi-display settings, their spatial configuration [43]. All of these recommendations are helpful, however, there seems little discussion of their importance relative to each other or any interplay between them.

\subsection{Attention and engagement in museums}

Outside the HCI literature, the field of museum studies has a considerable body of work on attention and engagement in museums [e.g. 4-7, 39-41], which includes detailed guidelines on both the design and placement of interpretive resources to support visitors' engagement and learning. While these guidelines typically refer to static print labels and tangible information displays, some explicitly refer to "all type of media [including] print, audio and graphics" and presentation formats including "interactivity, sound, graphics, video, computers" [40:1].

Some placement-related heuristics in this domain have clear equivalents in public display research. For instance, the recommendation to place labels "within line of sight so that visitors do not have to turn, look up high, or down low" [4:120] can be related to the heuristic that public displays installed at eye-height and in the direction of people's movement receive more attention [20:241]. Others demonstrate a more holistic perspective that takes into account people's overall visiting experience. Examples of the latter are the consideration of satiation and fatigue when visitors progress through a exhibition as critical factors affecting their attention and engagement $[6,7]$.

\subsection{Summary}

The HCI literature on ambient displays and interactive public displays, as well as domain-specific literature on attention and engagement with interpretive resources in the 
context of museum studies, offer useful models and heuristics that can inform both the design and placement of interactive displays such as SOLs. However, they typically focus on single characteristic rather than taking into account multiple characteristics and their interplay, and they give no indication as to the relative importance of designand placement-related factors. To address these aspects, we developed a method to quantify the attention potential of display placements based on multiple criteria, described in detail in [55], and in the present paper investigate how placement and design influence the levels of attention and engagement SOLs attract.

\section{Social Object Labels}

SOLs are an in-gallery commenting system designed to support visitor interpretation directly at the exhibit, when the experience is most immediate and most likely to prompt a response. The system consists of small (inch-scale [49]) interactive e-ink displays mounted next to exhibits, a related mobile application for visitors to add, browse, rate and flag comments, and an admin dashboard for museum staff to configure SOL displays, monitor their status and content, and moderate content flagged by visitors.
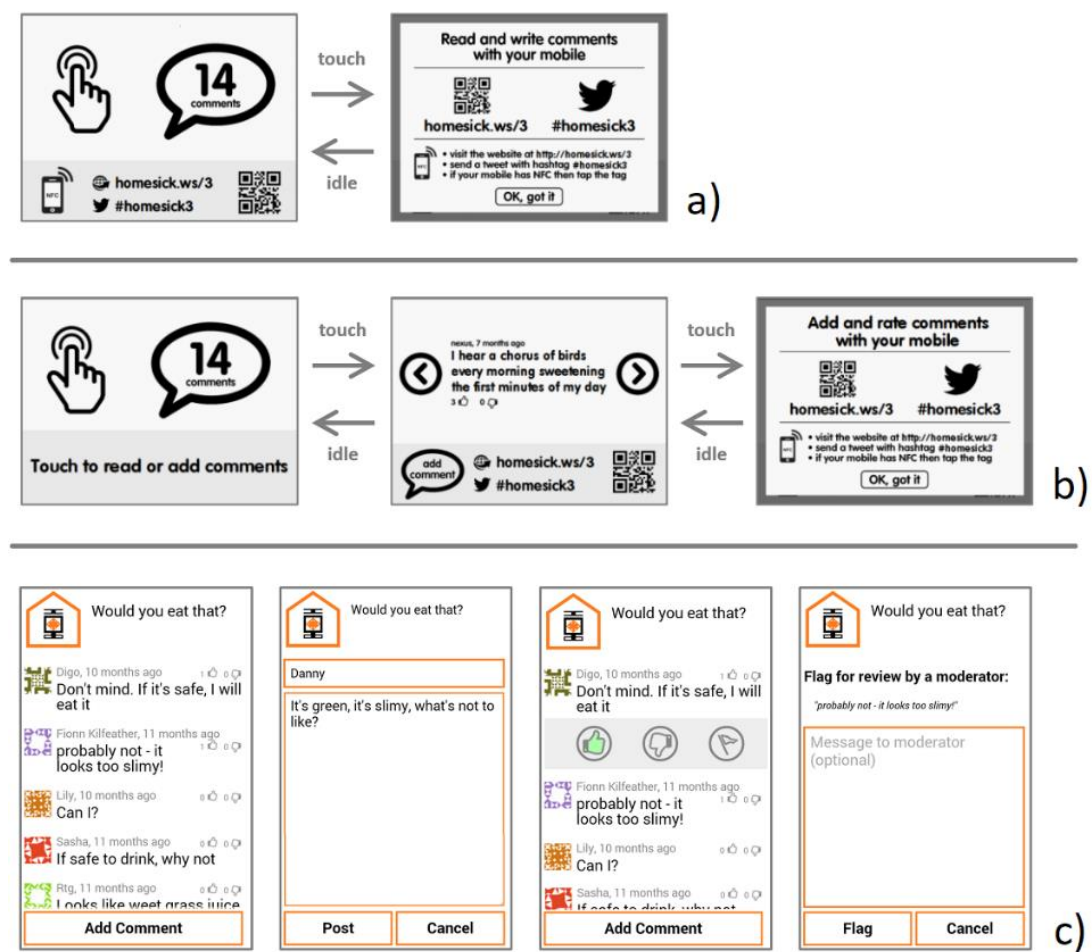

c)

Fig. 2. SOL interaction models including direct touch screen interaction (a) without content browsing and (b) with content browsing, and (c) mobile interaction to browse, add, rate and flag comments after connecting a mobile device via QR code, NFC or URL. 
SOL designs evolved over several iterations, informed by research into visitors' perspectives on commenting in museums [53], museum professionals' requirements for ingallery commenting platforms [54], a previous field trial at Science Gallery Dublin [56], as well as a theoretical design space analysis, technical prototyping, lab-based user testing and co-design sessions with users [52]. While a first evaluation [56] involved a version of SOLs limited to mobile interaction and a single design for all exhibits, the present field trial involves a version supporting both mobile and direct interaction on the SOL touch screen and a range of design variations that can be customized for specific exhibits.

Two models of direct interaction on the SOL touch screen were evaluated, one where the idle screen directly transitions to a help screen when touched (Fig 2a) and one where the idle screen transitions to a browse screen when touched, enabling visitors to browse submitted comments, which then transitions to a help screen when visitors touch the call to action or the connection information on the browse screen (Fig 2b). Both browse and help screens automatically revert to the idle screen when no interaction occurs for a certain time. In addition to touch screen interaction, SOLs also support mobile interaction, where visitors can browse, add, rate and flag comments (Fig 2c).

\section{$4 \quad$ Methodology}

In order to evaluate SOLs in a realistic gallery environment, a field trial was carried out at Science Gallery Dublin, involving the deployment of four SOL displays in an exhibition called Home Sick [38] for a duration of two weeks. As the field trial was part of a wider research effort exploring the design space for SOLs in museums, it was designed to evaluate a range of aspects relating to visitors' attention, engagement, interaction and mental models of SOLs, as well as their attitudes to technology use and visitor interpretation in museums. This paper focuses in particular on how display placement and design impact on visitors' attention and engagement with SOLs. Research questions include:

1. To what extent does display placement affect attention and engagement with SOLs? We hypothesize that placement is a critical factor in how much attention and engagement SOLs attract.

2. Can the impact of placement on attention and engagement with SOLs be predicted? We hypothesize that individual ratings for placement-related factors known to impact attention and engagement can be combined to quantify the overall attention potential of placements, which in turn can be used to predict attention and engagement with SOLs.

3. To what extent does the information and interaction design affect attention and engagement with SOLs? We hypothesize that support for direct interaction increases overall engagement and that designs supporting content browsing on the SOL touch screen, posing a questions to prompt and guide responses, or showing an image that relates the SOL to the exhibit and traditional object label, attract more attention and engagement than alternatives without these features. 
The following sections discuss the deployment of SOLs in the gallery, describe the evaluated designs and data collection, and present the findings of the field trial with respect to these questions.

\subsection{Placement in the gallery}

Four SOLs were installed in the gallery space, with the selection of exhibits guided by the idea of social objects, which provoke a reaction from visitors and stimulate debate $[13,42]$. Besides common considerations for interactive public displays, such as having a sustained flow of people and sufficient space for interaction around them [24] and installing them at a suitable height [17], the placement of SOLs was also influenced by available mounting options, fit with the local ensemble, agreement of artists for SOLs to be installed at their exhibit and conformance with health and safety regulations. Fig. 3 shows the four SOL installations in the order in which visitors would typically encounter them when making their way through the exhibition:

- SOL No.1 was integrated with an exhibit called Parasite Farm, which explores how agricultural practices can become part of urban living. The SOL was placed on an empty shelf in a book case holding plant boxes, occupying a central position and affording convenient access for direct interaction (Fig. 3a).
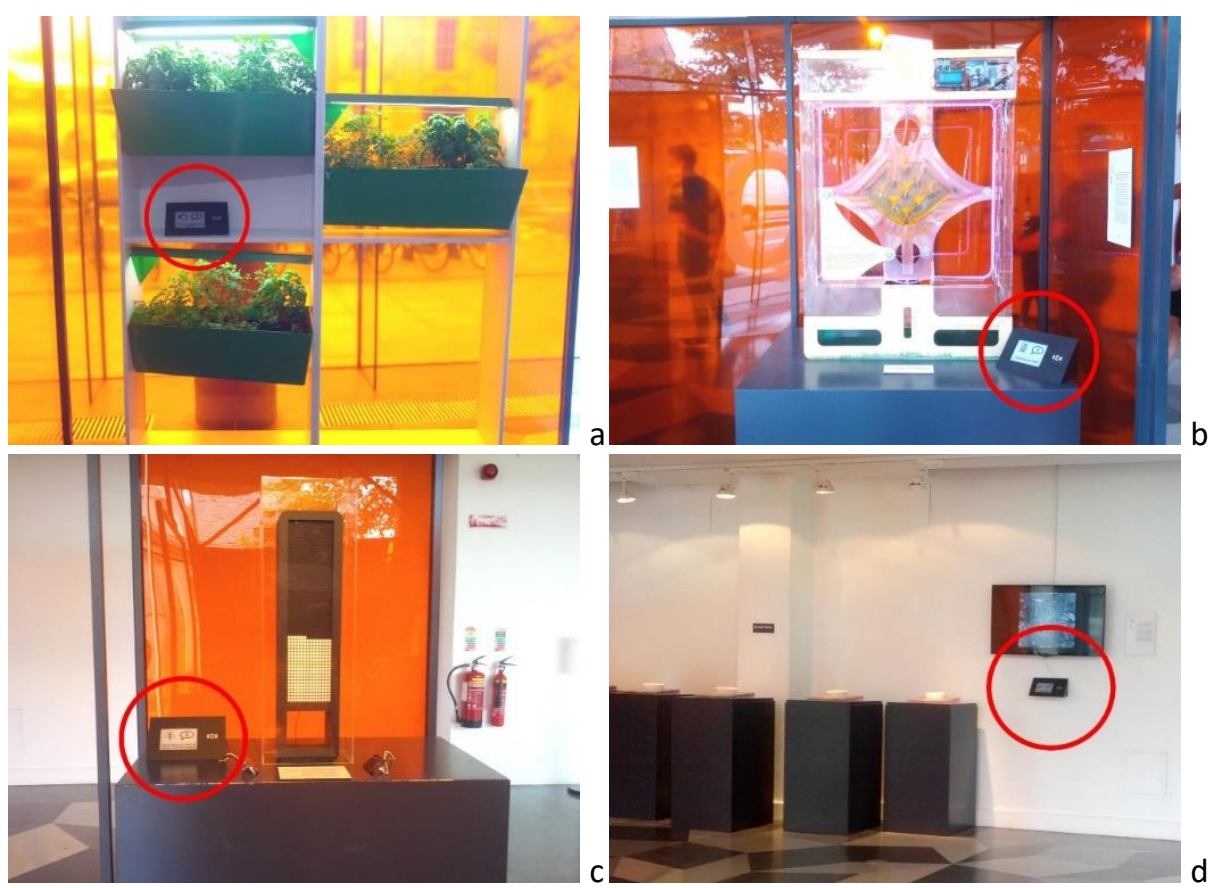

Fig. 3. SOLs (circled red) installed at four exhibits in the HomelSick exhibition at Science Gallery Dublin. (Images used with permission, originally published in [55]). 
- SOL No.2 was installed next to an exhibit called LillyBot 2.0, a personal microalgae farm that produces oxygen and Chlorella algae while binding carbon dioxide in the air. The SOL was placed to the right of the installation, requiring visitors to slightly bend down for direct interaction (Fig. 3b).

- SOL No.3 was integrated with an exhibit called Ritual Machines, which explores how technology can help to connect with family members away from home for extended periods. The SOL was placed next to a flip-dot matrix that can be controlled by visitors via two connected iPod touch devices, slightly set back but within easy reach of visitors operating the iPod on the left of the exhibit (Fig. 3c).

- SOL No.4 was installed next to an exhibit called Dust Matter(s), which conceptualizes domestic dust in the home as an indicator of the occupants' outdoor activities. The SOL was placed in a prominent position below a large video screen within easy reach for direct interaction (Fig. 3d).

In order to better understand how placement might affect attention and engagement with SOLs, a method described in [55] was used to quantify the attention potential of placement options. The method uses a subset of factors known to affect the level of attention exhibits and interpretation materials receive during a museum visit $[6,7]$ and provides a simple rating scale to quantify them for specific placements.

Table 1. Quantified attention potential of display placements based on individual ratings on a scale of 1 (low) to 4 (high) for aspects known to affect attention and engagement in museums.

\begin{tabular}{|c|c|c|c|c|c|c|c|c|c|c|c|c|c|c|c|}
\hline \multirow{3}{*}{ Distraction } & \multicolumn{4}{|c|}{ Parasite Farm } & \multicolumn{3}{|c|}{ LillyBot 2.0} & \multicolumn{4}{|c|}{ Ritual Machines } & \multicolumn{4}{|c|}{ Dust Matter(s) } \\
\hline & \multicolumn{4}{|c|}{$\begin{array}{l}\text { Little distraction } \\
\text { apart from pot- } \\
\text { plant above. }\end{array}$} & \multicolumn{3}{|c|}{$\begin{array}{l}\text { Sensor-driven } \\
\text { exhibit dominates } \\
\text { the scene. }\end{array}$} & \multicolumn{4}{|c|}{$\begin{array}{l}\text { Flip-dot display is } \\
\text { extremely eye- } \\
\text { catching. }\end{array}$} & \multicolumn{4}{|c|}{$\begin{array}{l}\text { Large video } \\
\text { screen dominates } \\
\text { the scene. }\end{array}$} \\
\hline & 1 & 2 & 3 & 4 & 1 & 2 & $3 \mid 4$ & 1 & 2 & 3 & 4 & 1 & 2 & 3 & 4 \\
\hline \multirow[t]{2}{*}{ Competition } & \multicolumn{4}{|c|}{$\begin{array}{l}\text { Little spatula to } \\
\text { dig in plant box } \\
\text { on shelf below. }\end{array}$} & \multicolumn{3}{|c|}{$\begin{array}{l}\text { Control a blender } \\
\text { by voice at exhibit } \\
\text { close by. }\end{array}$} & \multicolumn{4}{|c|}{$\begin{array}{l}\text { Two iPods to } \\
\text { control the flip- } \\
\text { dot display. }\end{array}$} & \multicolumn{4}{|c|}{$\begin{array}{l}\text { No interaction } \\
\text { possibilities close } \\
\text { to the exhibit. }\end{array}$} \\
\hline & 1 & 2 & 3 & 4 & 1 & 2 & \begin{tabular}{l|l}
3 & 4
\end{tabular} & 1 & 2 & 3 & 4 & 1 & 2 & 3 & 4 \\
\hline \multirow[t]{2}{*}{ Satiation } & \multicolumn{4}{|c|}{$\begin{array}{l}\text { First SOL } \\
\text { encountered in a } \\
\text { typical visit. }\end{array}$} & \multicolumn{3}{|c|}{$\begin{array}{l}\text { Second SOL } \\
\text { encountered in a } \\
\text { typical visit. }\end{array}$} & \multicolumn{4}{|c|}{$\begin{array}{l}\text { Third SOL } \\
\text { encountered in a } \\
\text { typical visit. }\end{array}$} & \multicolumn{4}{|c|}{$\begin{array}{l}\text { Fourth SOL } \\
\text { encountered in a } \\
\text { typical visit. }\end{array}$} \\
\hline & 1 & 2 & 3 & 4 & 1 & 2 & \begin{tabular}{l|l}
3 & 4 \\
\end{tabular} & 1 & 2 & 3 & 4 & 1 & 2 & 3 & 4 \\
\hline \multirow[t]{2}{*}{ Fatigue } & \multicolumn{4}{|c|}{$\begin{array}{l}\text { Third exhibit } \\
\text { encountered in a } \\
\text { typical visit. }\end{array}$} & \multicolumn{3}{|c|}{$\begin{array}{l}\text { Fourth exhibit } \\
\text { encountered in a } \\
\text { typical visit. }\end{array}$} & \multicolumn{4}{|c|}{$\begin{array}{l}\text { Sixth exhibit } \\
\text { encountered in a } \\
\text { typical visit. }\end{array}$} & \multicolumn{4}{|c|}{$\begin{array}{l}\text { Tenth exhibit } \\
\text { encountered in a } \\
\text { typical visit. }\end{array}$} \\
\hline & 1 & 2 & 3 & 4 & 1 & 2 & \begin{tabular}{l|l}
3 & 4 \\
\end{tabular} & 1 & 2 & 3 & 4 & 1 & 2 & 3 & 4 \\
\hline $\begin{array}{l}\text { Attention } \\
\text { potential }\end{array}$ & \multicolumn{4}{|c|}{$\frac{16-5}{16-4}=92 \%$} & \multicolumn{3}{|c|}{$\frac{16-\mathbf{1 0}}{16-4}=50 \%$} & \multicolumn{4}{|c|}{$\frac{16-\mathbf{1 4}}{16-4}=17 \%$} & \multicolumn{4}{|c|}{$\frac{16-\mathbf{1 2}}{16-4}=33 \%$} \\
\hline
\end{tabular}


All four factors relate to placement either in a local (exhibit) or global (gallery) context:

- Distraction: how many other stimuli are close by

- Competition: how much competition there is from other interaction opportunities

- Satiation: how often visitors have encountered a SOL in the gallery before

- Fatigue: at what stage during a visit they encounter the SOL

SOL installations were rated along each of these criteria before individual scores were combined to quantify the attention potential of each placement (Table 1).

\subsection{Evaluated designs}
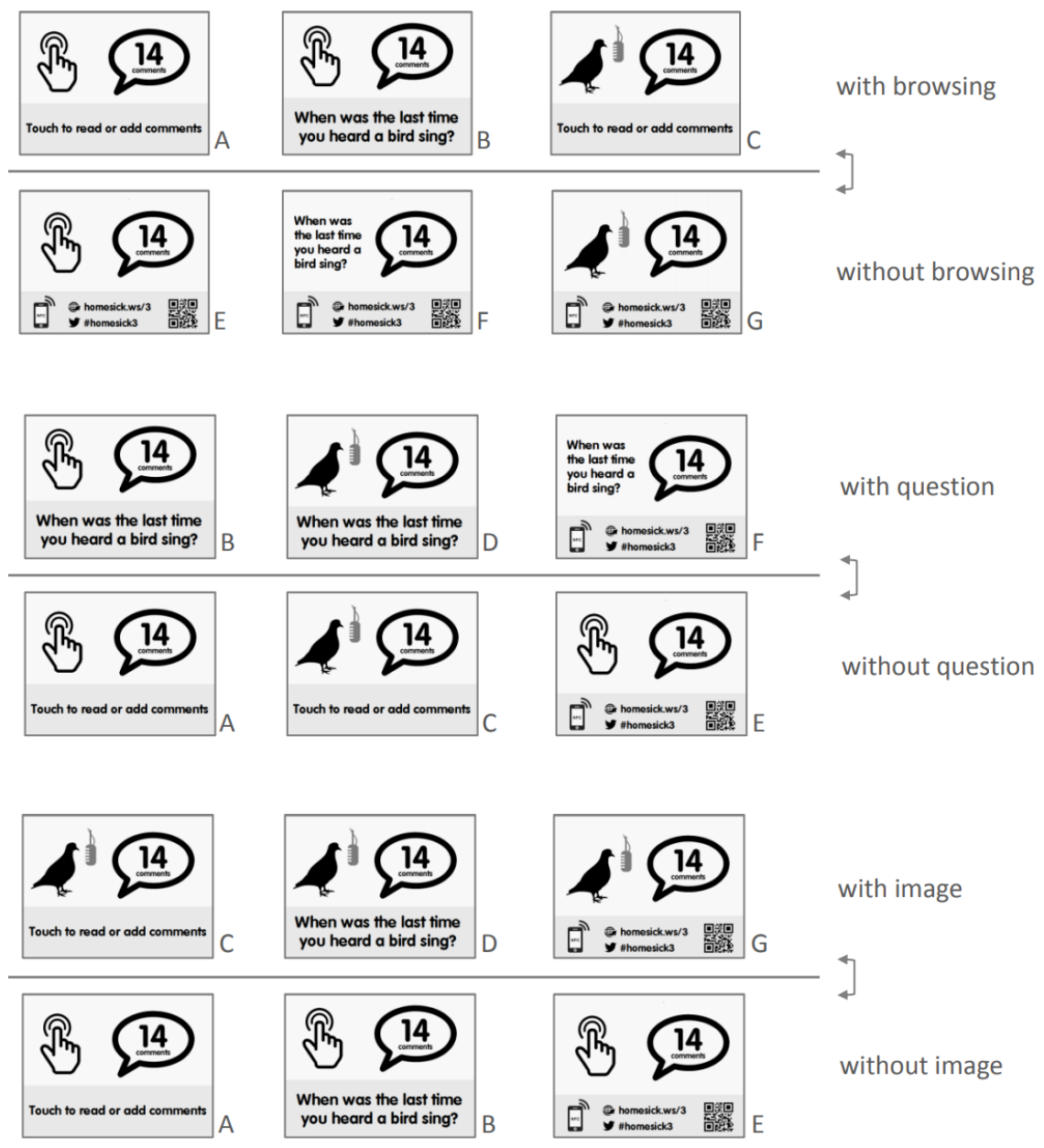

Fig. 4. Evaluated design variations A-G grouped into designs with/without content browsing on the SOL touch screen, with/without a question and with/without an exhibit-specific image. 
Evaluated design variations for the idle screen visitors encounter by default include versions with or without content browsing on the SOL touch screen, with or without a topical question to prompt visitor contributions, and with or without an image linking the SOL to the exhibit and traditional object label (Fig 4).

The field trial deliberately includes designs that vary in more than one parameter (e.g. designs with both image and question) and designs that implement features differently (e.g. designs with and without content browsing display the question in different ways). By exploring design variations in different combinations, the study embraces the multi-variant character of the naturalistic environment, where many of the contextual factors influencing visitors' attention and engagement with SOLs are beyond the researcher's control, and looks for findings that can be generalized beyond specific implementations and configurations.

In order for each design to have the same exposure with respect to exhibit, time of day and day of week, the installed SOLs automatically switched between designs following a fixed schedule. Layout switches took place at the midpoint of the daily gallery opening times for each day, resulting in two designs being active each day. Switches were synchronized to ensure that all SOLs in the gallery used the same design at any given time to leverage recognition and prior learning when visitors encounter them at different exhibits.

\subsection{Data collection and analysis}

Four data sets were used to assess attention and engagement with SOLs in the gallery. They include observations in the gallery, analytics data generated by SOL displays and the related mobile application, comments submitted to SOLs and in-house visitor numbers during the evaluation period collected via automatic visitor counters installed at Science Gallery Dublin.

Observations in the gallery. Observations were carried out without explicit consent by visitors in order not to disturb their natural behavior and focused specifically on attention and engagement with SOLs. The researcher's conduct during observation sessions was informed by the British Psychological Society's code of ethics, which restricts observations "... to those situations in which persons being studied would reasonably expect to be observed by strangers, with reference to local cultural values and to the privacy of persons who, even while in a public space, may believe they are unobserved." [10:13].

Observation notes were recorded in a coding template and then transferred into a spreadsheet for analysis. Quantitative data was summarized, segmented and analyzed using standard statistical methods for user research discussed in [37]. Qualitative observations were analyzed using a two-step emergent coding scheme described in [33] and then quantified where required.

Observations were carried out over six days with a combined observation time of 28 hours and 56 minutes, during which a total of 812 encounters were observed. Encounters are conceptualized as situations where visitors have a clear chance to notice and 
engage with a SOL. As a minimum, this involves a visitor stopping at an exhibit. Visitors might then look at the exhibit, read the object label, look at and engage with the SOL in various ways.

The recorded observations are not evenly distributed among exhibits, SOL designs and SOL states. The data was therefore segmented and analyzed for each exhibit and design variation, with attention and engagement rates expressed as percentage values of observed encounters for each condition.

Analytics data. Analytics data recording visitors' interaction with SOLs and the related mobile interaction was collected via an online API and related instrumentation of the client software. For direct interaction on the SOL touchscreen, interaction logs are structured into sessions. A session starts with a visitor touching the SOL idle screen, last as long as there is touch interaction on the browse or help screens and end when displays time out and return to the idle screen. For mobile interactions, logs are generated for individual events, which can then be grouped into sessions via an anonymous but unique device ID. Mobile interaction sessions start with visitors connecting their device to a SOL and last as long as they browse, add, edit, rate or flag comments.

A total of 2,421 interaction logs were collected during the evaluation period. The data was prepared for analysis by excluding direct interaction logs involving admin tasks (e.g. display configuration, initial screen activation) and mobile interaction logs from demonstrations (e.g. to show how NFC works). The latter were identified through device IDs relating to the researcher and gallery staff. The resulting set of 1,921 visitor interaction logs used to analyze engagement and interaction with SOLs include 1,612 direct interaction logs and 309 mobile interaction logs.

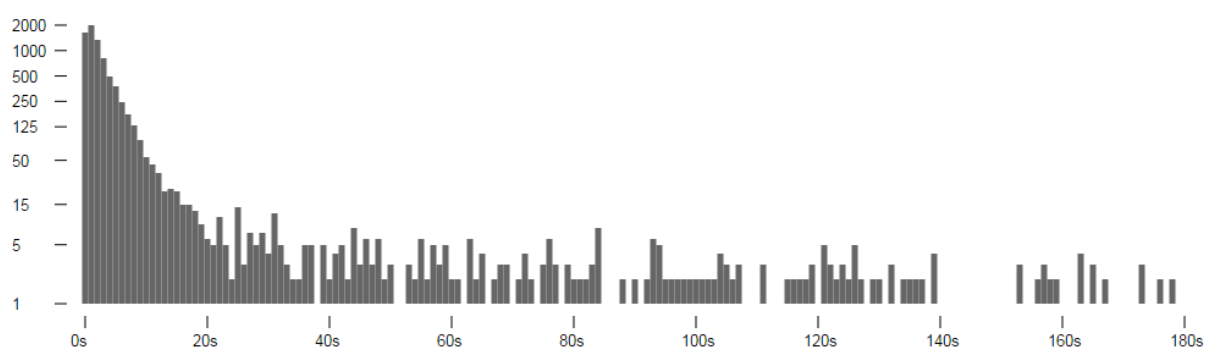

Fig. 5. Histogram of time intervals between interactions on SOL touch screen (logarithmic scale)

A key difference between mobile and direct interaction logs is that the former relate to specific users, identified by their device, while the latter are anonymous and can involve multiple visitors, e.g. when one visitor abandons the SOL and another engages before the screen times out. In order to approximate the number of visitors engaging via the SOL touch screen, it is therefore necessary to determine the number of user journeys in direct interaction session logs. For this purpose, a disengagement threshold was identified as the minimum time of inactivity after which it can be assumed that following interactions belong to a different user. This involved first classifying timing data into whole-second bins to analyze the distribution of time intervals between interactions (Fig. 5), and then using Jenks' natural breaks classification [21] to segment the 
time intervals into two clusters, representing touches during and between user journeys. The break point between these two clusters ( $55 \mathrm{~s}$ for designs with content browsing, $37 \mathrm{~s}$ for designs without content browsing) represents the disengagement threshold, which was used to determine the number of individual user journeys from direct interaction logs. Mobile interaction user journeys were determined simply by grouping mobile interaction $\operatorname{logs}$ by device ID and time. Total numbers based on 1,612 direct interaction logs and 309 mobile interaction logs include 2,031 direct interaction user journeys and 109 mobile interaction user journeys.

Submitted comments. Visitor comments submitted to SOLs refer to a specific exhibit (placement) and can be attributed to specific designs via their time of submission and related analytics data. While contribution rates are an obvious measure of engagement, the small number of contributions during the evaluation period $(n=21$, excluding seed comments) limits the reliability of any results based on this data set. It is included here nonetheless as it can give an indication of possible trends.

SGD visitor numbers. In order to establish a baseline of possible encounters with individual SOLs and design variations during the evaluation period, Science Gallery Dublin's in-house visitor numbers were consulted. The visitor numbers are based on automatic counters installed in the gallery and break down visits per day and time of day.

Table 2. Estimates of possible encounters with SOLs

\begin{tabular}{|l|r|l|r|r|}
\hline \multicolumn{2}{|c|}{ Possible encounters per placement } & \multicolumn{3}{r|}{ Possible encounters per design } \\
\hline & All screens & & All screens & Idle screen \\
\hline Parasite Farm & 2,822 & Design A & 2,602 & 1938 \\
\hline LillyBot 2.0 & 4,208 & Design B & 2,065 & 1538 \\
\hline Ritual Machines & 4,208 & Design C & 2,223 & 1656 \\
\hline Dust Matter(s) & 4,208 & Design D & 2,582 & 1923 \\
\hline Total & $\mathbf{1 5 , 4 4 6}$ & Design E & 1,878 & 1667 \\
\hline \multirow{2}{*}{} & Design F & 2,169 & 1925 \\
\cline { 2 - 5 } & Design G & 1,927 & 1710 \\
\cline { 2 - 5 } & Total & $\mathbf{1 5 , 4 4 6}$ & $\mathbf{1 2 , 3 5 7}$ \\
\cline { 3 - 5 } & & & & \\
& & & &
\end{tabular}

Estimates of possible encounters per SOL and design are shown in Table 2. They take into account total visitor numbers for the evaluation period $(4,208)$, daily visitor numbers, typical daily distribution of visitors over time, scheduled display times for specific SOL designs, down-times for SOL1 (Parasite Farm) due to a flat battery and the ratio between idle screen encounters and browse or help screen encounters from interaction logs. The estimates for possible encounters were used as a baseline to calculate engagement rates for SOL placements and designs from analytics data, allowing for triangulation with engagement rates from observations, which are based on actual rather than possible encounters. 


\section{$5 \quad$ Findings}

\subsection{Attention and engagement per exhibit (placement)}
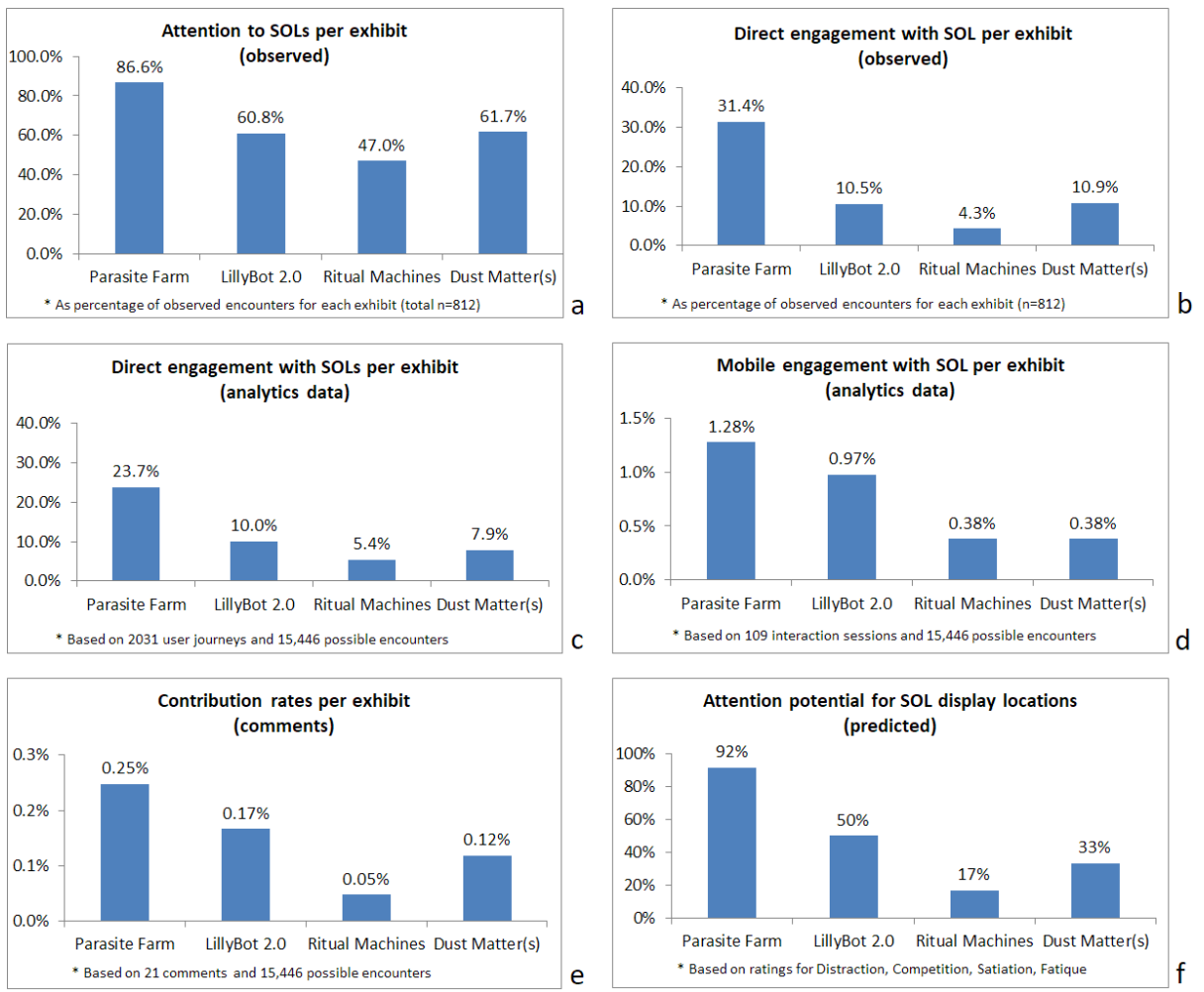

Fig. 6. Attention and engagement per exhibit: (a) observed attention, as number of people observed to look at SOL divided by number of encounters for that exhibit; (b) observed engagement, as number of people observed to engage with SOL divided by number of encounters for that exhibit; (c) engagement on SOL touch screen from analytics data, as number of user journeys on a SOL divided by number of potential encounters for that exhibit; (d) mobile engagement from analytics data, as number of mobile interaction sessions with a SOL divided by number of potential encounters for that exhibit; (e) contribution rates, as number of comments submitted to a SOL divided by number of potential encounters for that exhibit; and (f) the quantified attention potential for each SOL placement for reference.

The data shows marked differences in attention and engagement rates between exhibits, despite all SOLs using the same design at any given time. Attention and engagement per exhibit (and by extension per SOL placement) follow a similar pattern, suggesting that they are influenced by similar factors: 
- Observed attention to SOLs (Fig. 6a) is highest at Parasite Farm (86.6\%), decreases at Lillybot $2.0(60.8 \%)$, reaches its lowest point at Ritual Machines (47.0\%) and picks up again for Dust Matter(s) (61.7\%).

- Observed direct engagement with SOLs (Fig. 6b) is highest at Parasite Farm (31.4\%), decreases at Lillybot 2.0 (10.5\%), reaches its lowest point at Ritual Machines $(4.3 \%)$ and picks up again for Dust Matter(s) (10.9\%).

- Direct engagement with SOLs from analytics data (Fig. 6c) is highest at Parasite Farm $(23.7 \%)$, decreases at Lillybot 2.0 (10.0\%), reaches its lowest point at Ritual Machines (5.4\%) and picks up again for Dust Matter(s) $(7.9 \%)$.

- Mobile engagement with SOLs from analytics data (Fig. 6d) is highest at Parasite Farm (1.28\%), decreases at LillyBot 2.0 (0.97\%), reaches its lowest point at Ritual Machines $(0.38 \%)$ and stays at this level for Dust Matter(s).

- The contribution rate for SOLs (Fig. 6e) is highest at Parasite Farm (0.25\%), decreases at LillyBot $2.0(0.17 \%)$, reaches its lowest point at Ritual Machines $(0.05 \%)$ and increases again for Dust Matter(s) $(0.12 \%)$.

- For reference, Fig. 6f shows the quantified attention potential for each SOL placement as discussed above, which is highest at Parasite Farm (92\%), decreases at LillyBot $2.0(50 \%)$, reaches its lowest point at Ritual Machines (17\%) and increases again for Dust Matter(s) (33\%).

The data reflects visitors' qualified progression from attention to engagement to contribution, with large numbers failing to progress at each stage. Regardless of absolute numbers, the different data sets reveal a consistent pattern, suggesting they are influenced by similar factors. There are strong and significant correlations between observed attention and observed direct engagement $(r=0.99, t=8.69, p<0.01)$, engagement rates from analytics data $(\mathrm{r}=0.97, \mathrm{t}=5.52, \mathrm{p}<0.01)$ and contribution rates $(\mathrm{r}=0.96, \mathrm{t}$ $=4.56, \mathrm{p}<0.01)$. The only data set not strongly and significantly correlating to observed attention is mobile engagement $(r=0.83, t=2.08, p=0.08)$, which remains flat between Ritual Machines and Dust Matter(s). While this might be attributed to the small number of people who engaged in mobile interaction, an alternative interpretation is that the additional physical and cognitive effort associated with connecting a mobile device to the display becomes more relevant in the later stages of a visit when museum fatigue $[6,7,12]$ sets in.

\subsection{Predicted vs measured attention and engagement}

Regarding the predictive power of the quantified attention potential for each SOL placement, the data shows strong and significant correlations (Table 3) not only between attention potential and observed attention rates but also between attention potential and observed direct engagement, direct engagement from analytics data, mobile engagement and contribution rates (Fig. 7). While these correlations do not imply causality, they suggests that placement-related factors are a good indicator of how much attention and engagement a display receives. 
Table 3. Correlation between attention potential and measured attention and engagement. (Table used with permission, originally published in [55]).

\begin{tabular}{|l|c|c|c|c|c|c|}
\cline { 2 - 7 } \multicolumn{1}{c|}{} & $\begin{array}{c}\text { Attention } \\
\text { potential }\end{array}$ & $\begin{array}{c}\text { Attention } \\
\text { (observed) }\end{array}$ & $\begin{array}{c}\text { Direct Eng. } \\
\text { (observed) }\end{array}$ & $\begin{array}{c}\text { Direct Eng. } \\
\text { (analytics) }\end{array}$ & $\begin{array}{c}\text { Mobile Eng. } \\
\text { (analytics) }\end{array}$ & $\begin{array}{c}\text { Contrib. } \\
\text { (comments) }\end{array}$ \\
\hline Parasite Farm & $91.7 \%$ & $86.6 \%$ & $31.4 \%$ & $23.7 \%$ & $1.28 \%$ & $0.25 \%$ \\
\hline LillyBot 2.0 & $50.0 \%$ & $60.8 \%$ & $10.5 \%$ & $10.0 \%$ & $0.97 \%$ & $0.17 \%$ \\
\hline Ritual Machines & $16.7 \%$ & $47.0 \%$ & $4.3 \%$ & $5.4 \%$ & $0.38 \%$ & $0.05 \%$ \\
\hline Dust Matter(s) & $33.3 \%$ & $61.7 \%$ & $10.9 \%$ & $7.9 \%$ & $0.38 \%$ & $0.12 \%$ \\
\hline \hline Correlation $\boldsymbol{r}$ & - & 0.972 & 0.967 & 0.978 & 0.936 & 0.982 \\
\hline t-value & - & 5.802 & 5.387 & 6.675 & 3.755 & 7.315 \\
\hline p-value & - & 0.0011 & 0.0017 & 0.0005 & 0.0094 & 0.0003 \\
\hline
\end{tabular}

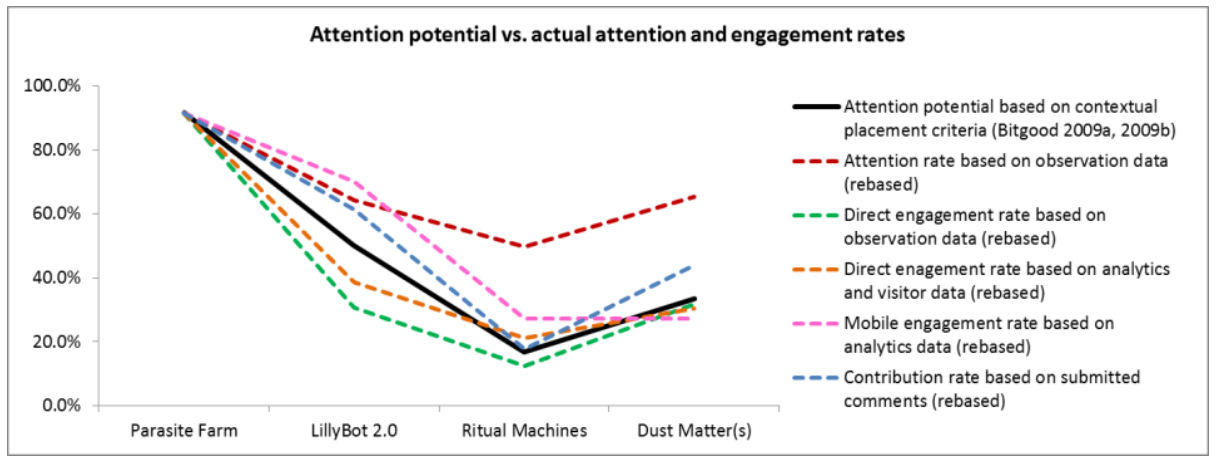

Fig. 7. Correlation between attention potential and measured attention and engagement. The diagram shows values proportionally rebased to the attention potential of Parasite Farm. (Diagram used with permission, originally published in [55]).

While the correlation is based on only four data points per series and the predicted attention potential on only four placement-related criteria, the results are promising and warrant future research into validating this method and adapting in for other environments. Potential benefits include using quantified attention potential as an additional vector to inform object selection and local display placement, as a baseline to scope expectations about attention and engagement with displays, and to inform mitigating design choices, e.g. using a more luminous display or a more conspicuous casing to compensate for the low attention potential of a placement.

\subsection{Attention and engagement per design}

Reflecting the fact that design variations pertain primarily to the idle screen (Fig. 4) rather than browse or help screens, the measured attention and engagement rates per design are based on interaction sessions, which always start with the idle screen, rather than user journeys, which can equally start with browse or help screens encountered by 
visitors when a SOL was abandoned by a previous user and has not yet timed out and reverted to the idle screen. Accordingly, the baseline for engagement rates per design are potential encounters with SOL idle screens rather than potential encounters with SOLs in general (Table 2).

The results provide a mixed picture regarding visitors' attention and engagement with the evaluated SOL designs, not always supporting reliable conclusions about the effectiveness of related design parameters. Table 4 shows that in many cases the differences in attention and engagement rates between these designs did not reach a level of statistical significance. This applies in particular to observed attention, mobile engagement and contribution rates, the latter two mainly due to the small numbers involved. The following paragraphs focus on the four design variations where differences in engagement rates did reach a significant level:

Fig. $8 \mathrm{~b}$ shows that direct engagement rates were higher for designs with browsing $(13.7 \%)$ than for designs without browsing (12.2\%). While the difference is small $(1.5 \%)$, it is statistically significant $(\mathrm{p}=0.014)$ and suggests that designs with browsing are overall a better choice in terms of encouraging visitor engagement. However, given that these engagement rates reflect engagement with the idle screen, it can be assumed that it is not the browsing functionality itself causing higher engagement rates but related differences in the idle screen design, which shows a question or call to action for designs with browsing, as opposed to information on how to connect a mobile phone for designs without browsing (Fig. 4). This assumption is supported by numbers including encounters with browse and help screens and using all possible encounters as baseline, which results in engagement rates of $11.8 \%$ for designs with browsing and $11.1 \%$ for designs without browsing, not reaching statistical significance $(\mathrm{p}=0.153)$. The results suggest that a question or call to action is more effective in encouraging direct interaction on the SOL touch screen than information explaining how to connect a mobile phone to browse and add comments.

Fig. 8f shows that direct engagement rates were lower for designs with a question $(12.1 \%)$ than for designs without a question $(13.7 \%)$. The difference of $1.6 \%$ is statistically significant $(\mathrm{p}=0.009)$ and suggests that designs asking a question to prompt and focus visitor responses are less effective in encouraging visitor engagement on the SOL touch screen than designs showing a call to action.

Fig. 8j shows that direct engagement rates were lower for designs with an image $(11.6 \%)$ than for designs without an image (14.1\%). The difference of $2.5 \%$ is statistically significant $(\mathrm{p}<0.001)$ and suggests that designs showing an image linking the SOL to the exhibit are less effective in encouraging visitor engagement on the touch screen than designs showing a generic icon visually communicating support for touch screen interaction.

Fig. $8 \mathrm{~h}$ shows that contribution rates were higher for designs with a question $(0.22 \%)$ than for designs without a question $(0.07 \%)$. The difference of $0.15 \%$ is statistically significant $(\mathrm{p}=0.025)$ and suggests that designs asking a question to prompt and focus visitor responses are more effective in encouraging visitors to submit a comment than designs showing a generic call to action. However, due to the overall low number of comments submitted during the evaluation period $(n=21)$ more data is required to confirm this interpretation. 
Table 4. Attention, direct engagement, mobile engagement and contribution rates for SOL designs with or without browsing, with or without question and with or without image; $p$ values indicate significance of the differences between these conditions.

\begin{tabular}{|c|c|c|c|c|c|c|c|c|}
\hline \multirow[b]{2}{*}{$\begin{array}{l}\text { With browsing } \\
(\mathbf{A}, \mathbf{B}, \mathbf{C}, \mathbf{D})\end{array}$} & \multicolumn{2}{|c|}{$\begin{array}{l}\text { Attention } \\
\text { (observed) }\end{array}$} & \multicolumn{2}{|c|}{$\begin{array}{l}\text { Direct Eng. } \\
\text { (analytics) }\end{array}$} & \multicolumn{2}{|c|}{$\begin{array}{l}\text { Mobile Eng. } \\
\text { (analytics) }\end{array}$} & \multicolumn{2}{|c|}{$\begin{array}{l}\text { Contrib. rate } \\
\text { (comments) }\end{array}$} \\
\hline & $63.7 \%$ & \multirow{2}{*}{$\begin{array}{c}\mathrm{p}= \\
0.113\end{array}$} & $13.7 \%$ & \multirow{2}{*}{$\begin{array}{c}\mathrm{p}= \\
0.014\end{array}$} & $0.79 \%$ & \multirow{2}{*}{$\begin{array}{c}\mathrm{p}= \\
0.226\end{array}$} & $0.17 \%$ & \multirow{2}{*}{$\begin{array}{c}p= \\
0.996\end{array}$} \\
\hline $\begin{array}{l}\text { Without browsing } \\
(\mathbf{E}, \mathbf{F}, \mathbf{G})\end{array}$ & $57.7 \%$ & & $12.2 \%$ & & $1.00 \%$ & & $0.17 \%$ & \\
\hline $\begin{array}{l}\text { With question } \\
(\mathbf{B}, \mathbf{D}, \mathbf{F})\end{array}$ & $60.7 \%$ & \multirow{2}{*}{$\begin{array}{c}\mathrm{p}= \\
0.895\end{array}$} & $12.1 \%$ & \multirow{2}{*}{$\begin{array}{c}\mathrm{p}= \\
0.009\end{array}$} & $0.89 \%$ & \multirow{2}{*}{$\begin{array}{c}\mathrm{p}= \\
0.924\end{array}$} & $0.22 \%$ & \multirow{2}{*}{$\begin{array}{c}\mathrm{p}= \\
0.025\end{array}$} \\
\hline $\begin{array}{l}\text { Without question } \\
\text { (A,C,E,G) }\end{array}$ & $61.2 \%$ & & $13.7 \%$ & & $0.88 \%$ & & $0.07 \%$ & \\
\hline $\begin{array}{l}\text { With image } \\
(\mathbf{C}, \mathrm{D}, \mathrm{G})\end{array}$ & $63.3 \%$ & \multirow{2}{*}{$\begin{array}{c}\mathrm{p}= \\
0.220\end{array}$} & $11.6 \%$ & \multirow{2}{*}{$\begin{array}{c}\mathrm{p}< \\
0.001\end{array}$} & $0.76 \%$ & \multirow{2}{*}{$\begin{array}{c}\mathrm{p}= \\
0.196\end{array}$} & $0.15 \%$ & \multirow{2}{*}{$\begin{array}{c}\mathrm{p}= \\
0.951\end{array}$} \\
\hline $\begin{array}{l}\text { Without image } \\
(\mathbf{A}, \mathbf{B}, \mathbf{E}, \mathbf{F})\end{array}$ & $58.6 \%$ & & $14.1 \%$ & & $0.98 \%$ & & $0.16 \%$ & \\
\hline
\end{tabular}

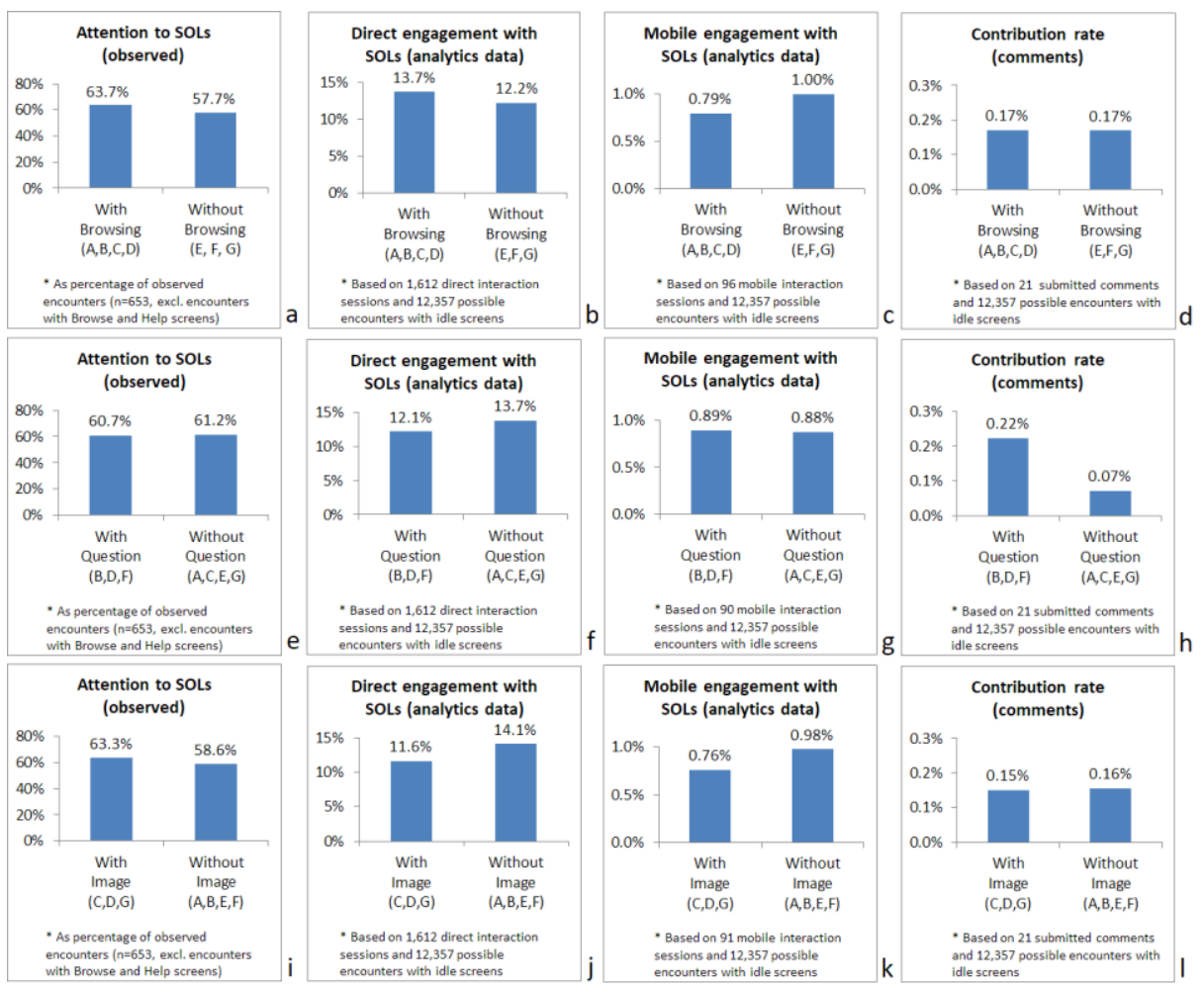

Fig. 8. Attention, direct engagement, mobile engagement and contribution rates for SOL designs (a-d) with or without browsing, (e-h) with or without question and (i-l) with or without image. 


\subsection{Discussion}

The results provide clear answers to some of the research questions in this study while not supporting any firm conclusions for others.

Regarding the question to what extent the placement of SOLs affects visitors' attention and engagement with them, the results show significant differences in attention and engagement rates between individual SOL installations, which far outweigh the small and at times insignificant differences between design variations. They confirm that placement is a critical factor in how much attention and engagement SOLs attract, and are in line with reports in the literature emphasizing the importance of placement-related factors on attention and engagement with public displays [9, 11, 20, 24, 43] and with exhibits and interpretation materials in museums [4-7].

Regarding the question whether the impact of placement on visitors' attention and engagement with SOLs can be predicted, we applied a method to quantify the attention potential of display placements described in [55] to each of the four SOL installations in the gallery. The results show strong and significant correlations between the predicted attention potential and measured attention and engagement. While the correlation is based on only four data points per series and does not imply causality, it seems to support the hypothesis that ratings of individual placement-related factors can be combined to quantify an attention potential that can predict the level of attention and engagement SOLs receive. If these predictive qualities can be confirmed in further studies, the attention potential of placements can become an additional vector informing object selection and local positioning, and help to evaluate the effectiveness of SOL deployments by providing a baseline for attention and engagement.

Regarding the question how information and interaction design affect attention and engagement with SOLs, the results provide qualified support for some hypotheses while rejecting others. The results show no significant differences in attention rates between design variations, however, they do show significant differences in direct engagement rates:

- The results confirm the hypothesis that designs supporting direct interaction attract more engagement than designs without content browsing. While the data does not support any conclusions about the effectiveness of interaction models per se in encouraging engagement, it clearly shows that designs displaying questions or calls to action on the idle screen have significantly higher direct engagement rates than designs displaying information how to connect a mobile device via a QR code, NFC and URL. This is in line with earlier findings of some museum visitors having negative attitude towards QR codes, leading them to ignore interaction opportunities, and the need to de-emphasize technical aspects in the user interface [56].

- The results reject the hypothesis that designs posing a question to prompt visitors and focus their responses attract more engagement than designs showing a generic call to action. Instead, the data shows that designs with a generic call to action have significantly higher direct engagement rates than designs posing a question, even though some of the underlying reasoning for posing a question is vindicated by designs with a question having higher contribution rates than designs with a generic prompt. Together, these findings support claims in the literature that questions can 
encourage visitor interpretation by directing and scaffolding responses [42], however, they also show that generic calls to action are a more effective way to encourage engagement with SOLs in first place.

- The results reject the hypothesis that designs showing an image relating the SOL to the exhibit and object label attract more engagement than designs showing a generic touch screen icon. Instead, the data shows that designs with a generic touch screen icon have significantly higher direct engagement rates than designs showing an exhibit-specific image. While not denying that the image helped to integrate SOLs with the local information environment [8] of exhibits, it clearly shows that this does not necessarily translate to increased engagement.

Overall, the findings support some of our assumptions how placement and design affect attention and engagement with SOLs, while they qualify and reject others. Placement clearly has a strong impact on attention and various engagement measures, outweighing any effects of interaction and information design. The results also suggest that attention and engagement can be predicted, at least in a gallery context, by assessing the attention potential of placements using the method proposed in [55]. By comparison, the effects of design variations are less pronounced, only producing significant differences for some engagement measures while being inconclusive for others.

\section{$6 \quad$ Limitations}

In line with calls in the literature that ubiquitous computing technologies should be evaluated in realistic environments $[1,2,18]$, the emphasis of this study was on ecological validity, as reflected in the live gallery deployment and non-obtrusive data collection. As a consequence, however, the research is subject to the museum's constraints, practices and natural visitor flow, limiting control over important parameters. In addition, the limited timeframe in which the study was carried out further constrained the research design. Limitations relating to one or more of these factors include:

- The study does not involve clear A/B testing as the evaluated designs vary in more than one parameter as well as their exact implementation. While this decreases internal validity, it increases external validity by exploring design variations in different combinations, making it more likely that findings can be generalized beyond specific configurations.

- The study involves a large number of observations, however, it can be difficult to reliably judge from observations whether someone looks at and actually notices a SOL, which introduces an error margin for observed attention rates.

- Engagement rates are based on user journeys and potential encounters, both of which are approximations. In order to avoid overstating engagement rates, minimum values for user journeys and maximum values for potential encounters were used.

- The low levels of mobile engagement and content contribution against the large number of potential encounters makes conventional thresholds for statistical significance problematic, reducing the validity of results relating to these data sets. 
- The attention potential of SOL installations is based on a subset of placement-related factors identified in $[6,7]$ to affect visitors' attention in museums, but is likely to be influenced by many other factors. The strong and significant correlation with actual attention and engagement rates is based on only four installations and does not imply causality. More research is needed to integrate additional factors influencing attention potential and to assess the validity and utility of the method.

With regard to transferability, many findings of this evaluation are general enough to be applicable to other contexts and environments. While emerging from a study investigating attention and engagement with SOLs in particular, it is hoped that they are useful to researchers exploring other interactive public display concepts.

\section{Conclusions}

Drawing on heuristics and guidelines in the literature describing how placement- and design-related factors impact on people's attention and engagement with public displays on the one hand, and with interpretation resources in museums on the other hand, this paper reports findings from an empirical study evaluating the effects of placement and design in a field trial of SOLs at Science Gallery Dublin.

It confirms placement as a key factor in how much attention and engagement displays receive and suggests that attention and engagement rates can be predicted by quantifying the attention potential of placements. The proposed method to quantify the attention potential of placements [55] combines ratings along four aspects known to affect attention and engagement in a museum context, however, the principle of combining ratings for several factors to quantify an attention potential easily transfers to other contexts, warranting further research into adapting the method to incorporate other placement-related factors described in the literature and evaluating it with more deployments and in different environments.

Putting into perspective the importance of design-related heuristics discussed in the literature, the field trial found that variations in the interaction- and information-design of SOLs had no significant effect on attention rates and only minor effects reaching significance on some engagement metrics. Specifically, they indicate that designs showing a generic call to action, displaying a touch screen icon and not presenting technical information on the idle screen attract more direct engagement on the SOL touch screen than designs posing a question, displaying an exhibit-specific image or presenting technical information how to connect a mobile device. They also indicate that designs posing a questions attract more contributions, vindicating recommendations in the literature in this respect [42], but otherwise found no significant differences between designs for other engagement measures.

Despite the limitations discussed above, this paper makes important contributions by showing with high ecological validity that display placement has an overriding effect on attention and engagement, and that this effect can be predicted to some degree by quantifying the attention potential of display placements. This can help to scope 
expectations about attention and engagement for specific deployments and support public display evaluations by putting into context design-related factors that might impact on specific engagement metrics.

While the study involved SOLs as a specific instance of interactive displays, deployed in a gallery environment as a specific instance of a public use environment, many of is findings are general enough to be relevant to other display types and environments. They warrant future research developing more general methods to quantify the attention potential of display placements, advancing our understanding how placement and design influence attention and engagement, and helping towards increasing the effectiveness and impact of public display applications.

Acknowledgements. We would like to thank Science Gallery Dublin for sharing their valuable insights and supporting this research during the field trial. We also thank visitors to the HomelSick exhibition for unwittingly supporting this research with their curiosity and engagement in the gallery space.

\section{References}

1. Abowd, G.: What next, ubicomp? Celebrating an intellectual disappearing act. In Proc. of 14th Int. Conf. on Ubiquitous Computing, 1-10. ACM (2012).

2. Abowd, G., Mynatt, E.: Charting past, present, and future research in ubiquitous computing. ACM Transactions on Computer-Human Interaction, 7(1), 29-58. (2000).

3. Ames, M., Dey, A.: Description of design dimensions and evaluation for Ambient Displays. Technical Report CSD-02-1211. EECS Department, University of California (2002). http://www.eecs.berkeley.edu/Pubs/TechRpts/2002/6193.html. Last accessed 2020/05/24.

4. Bitgood, S.: The ABCs of label design. Visitor Studies: Theory, Research, and Practice, 3(1), 115-129. (1991).

5. Bitgood, S.: The Role of Attention in Designing Effective Interpretive labels. Journal of Interpretation Research, 5(2), 31-45. (2000).

6. Bitgood, S.: Museum Fatigue: A Critical Review. Visitor Studies, 12(2), 93-111. (2009).

7. Bitgood, S.: When Is "Museum Fatigue" Not Fatigue? Curator, 52(2), 193-202. (2009).

8. Brewer, J.: Factors In Designing Effective Ambient Displays. In Proc. of 6th Int. Conf. on Ubiquitous Computing, 1-2. ACM (2004).

9. Brignull, H., Rogers, Y.: Enticing People to Interact with Large Public Displays in Public Spaces. In Proc. of 9th Int. Conf. on Human-Computer Interaction, 1-5. IOS Press (2003).

10. British Psychological Society: Code of Ethics and Conduct. BPS (2009). Available: https://www.bps.org.uk/files/code-ethics-and-conduct-2009pdf. Last accessed 2020/05/24.

11. Cheverst, K., Fitton, D., Dix. A.: Exploring the Evolution of Office Door Displays. In O'Hara, K. et al. (Eds.) Public and Situated Displays: Social and Interactional aspects of shared display technologies, Ch. 6. Kluwer (2003).

12. Davey, G.: What is museum fatigue? Visitor Studies Today, 8(3), 17-21. (2005)

13. Engeström, J.: Why some social network services work and others don't - Or: the case for object-centered sociality. Blog post 13 April 2005. http://www.zengestrom.com/blog/2005 /04/why-some-social-network-services-work-and-others-dont-or-the-case-for-object-centered-sociality.html. Last accessed 2020/05/24. 
14. Falk, J. H., Dierking, L. D.: Learning from Museums. Visitor Experiences and the Making of Meaning, Walnut Creek: AltaMira Press (2000).

15. Finke, M., Tang, A., Leung, R., Blackstock, M.: Lessons Learned: Game Design for Large Public Displays. In Proc. of 3rd Int. Conf. on Digital Interactive Media in Entertainment and Arts, 10-12. ACM (2008).

16. Greenberg, S.: Opportunities for Proxemic Interactions in Ubicomp (Keynote). In Proc. of 13th Conf. on Human-Computer Interaction, 3-10. Springer (2011).

17. Hardy, R., Rukzio, E., Holleis, P., Wagner, M.: Mobile interaction with static and dynamic NFC-based displays. In Proc. of 12th Int. Conf. on Human Computer Interaction with Mobile Devices and Services, 123-132. ACM (2010).

18. Hazlewood, W. R., Coyle, L.: On Ambient Information Systems. Int. Journal of Ambient Computing and Intelligence, 1(2), 1-12. (2009).

19. Hein, G.E.: The constructivist museum. Journal of Education in Museums, 16, 21-23. (1995).

20. Huang, E., Koster, A., Borchers, J.: Overcoming assumptions and uncovering practices: When does the public really look at public displays? In Proc. of Int. Conf. on Pervasive Computing, 228-243. Springer ( 2008).

21. Jenks, G.F.: The Data Model Concept in Statistical Mapping, Int. Yearbook of Cartography 7, 186-190. (1967).

22. José, R., Huang, E. (Eds.). In Proc. of Int. Symposium on Pervasive Displays. ACM (2012).

23. Kearsley, G.: Public Access Systems: Bringing Computer Power to the People. Ablex Publishing Corporation (1994).

24. Kules, B., Kang, H., Plaisant, C., Rose, A.: Immediate usability: a case study of public access design for a community photo library. Interacting with Computers, 16(6), 1171-1193. (2004).

25. Mack, A., Rock, I.: Inattentional blindness (Vol. 33). MIT press (1998).

26. Mankoff, J., Dey, A.: A Practical Guide to Designing Ambient Displays. In K. Ohara and E. Churchill (Eds.), Public and Situated Displays, 1-21. Kluwer (2003).

27. Matthews, T., Rattenbury, T., Carter, S., Dey, A., Mankoff, J.: A Peripheral Display Toolkit. Technical Report No. UCB/CSD-03-1258. University of California (2003).

28. Matthews, T. L., Forlizzi, J., Rohrbach, S.: Designing Glanceable Peripheral Displays. Technical Report No. UCB/EECS-2006-113. University of California (2006).

29. Matthews, T., Rattenbury, T., Carter, S.: Defining, designing, and evaluating peripheral displays: An analysis using activity theory. Human-Computer Interaction, 22(1-2), 221-261. (2007)

30. Maye, L. A., McDermott, F. E., Ciolfi, L., Avram, G.: Interactive Exhibitions Design - What Can We Learn From Cultural Heritage Professionals? In Proc. of 8th Nordic Conf. on Human-Computer Interaction, 598-607. ACM (2014)

31. McLean, K.: Museum Exhibitions and the Dynamics of Dialogue. Daedalus, 128(3), 83107. (1999).

32. Michelis, D., Müller, J.: The Audience Funnel: Observations of Gesture Based Interaction With Multiple Large Displays in a City Center. Int. Journal of Human-Computer Interaction, 27(6), 562-579. (2011).

33. Miles, M.B., Huberman, A.M.: Qualitative Data Analysis. Newbury Park, CA: Sage (1984).

34. Müller, J., Alt, F., Michelis, D., Schmidt, A.: Requirements and design space for interactive public displays. In Proc. of 18th Int. Conf. on Multimedia, 1285-1294. ACM (2010).

35. Peters, C., Castellano, G., de Freitas, S.: An exploration of user engagement in HCI. In Proc. of Int. Workshop on Affective-Aware Virtual Agents and Social Robots, 1-3. ACM (2009). 
36. Sandell, R.: Social inclusion, the museum and the dynamic of sectoral change. Museum and Society, 1(1), 45-62. (2003).

37. Sauro, J., Lewis, J.R.: Quantifying the User Experience. Morgan Kaufmann (2012).

38. Science Gallery Dublin: HomelSick: Post-Domestic Bliss. Science Gallery Dublin (2015). https://dublin. sciencegallery.com/homesick/. Last accessed 2020/05/24.

39. Screven, C.G.: The Museum as a Responsive Learning Environment. Museum News, 47(10), 7-10. (1969).

40. Screven, C.G.: Motivating Visitors to Read Labels. ILVS Review, 2(2), 183-211. (1992).

41. Serrell, B.: Exhibit Labels: An Interpretive Approach. Alta Mira Press (1996).

42. Simon, N.: The participatory museum. Museum 2.0 (2010). http://www.participatorymuseum.org/. Last accessed 2020/05/24.

43. Ten Koppel, M., Bailly, G., Müller, J., Walter, R.: Chained displays: Configurations of public displays can be used to influence actor-, audience-, and passer-by behavior. In Proc. of SIGCHI Conf. on Human Factors in Computing Systems, 317-326. ACM (2012).

44. Tomittsch, M., Kappel, K., Lehner, A., Grechenig, T.: Towards a Taxonomy for Ambient Information Systems. In Proc. of 5th Int. Conf. on Pervasive Computing, 44. Springer (2007).

45. Tröndle, M., Wintzerith, S.: A museum for the twenty-first century: the influence of "sociality" on art reception in museum space. Museum Management and Curatorship, 27(5), 461486. (2012).

46. Vom Lehn, D., Heath, C.: Displacing the Object: Mobile Technologies and Interpretive Resources. Archives \& Museum Informatics, 2. (2003).

47. Wang, M., Boring, S., Greenberg, S.: Proxemic peddler: a public advertising display that captures and preserves the attention of a passerby. In Proc. of Int. Symposium on Pervasive Displays, 1-6. ACM (2012)

48. Weil, S.E.: From Being about Something to Being for Somebody: The Ongoing Transformation of the American Museum. Daedalus, 128(3), 229-258. (1999).

49. Weiser, M.: The computer for the 21st century. Scientific American, 3(3), 3-11. (1991).

50. Weiser, M., Seely Brown, J.: Designing calm technology. PowerGrid Journal, 1.01, 1-5. (1996)

51. Winter, M.: Social Object Labels: Supporting Social Object Annotation with Small Pervasive Displays. In Proc. of Int. Conf. on Pervasive Computing and Communications, 489494. IEEE (2014).

52. Winter, M.: A design space for social object labels in museums. PhD Thesis. School of Computing, Engineering and Mathematics, University of Brighton (2016).

53. Winter, M.: Visitor perspectives on commenting in museums. Museum Management and Curatorship, 33(5), 484-505. (2018).

54. Winter, M.: Requirements for an in-gallery social interpretation platform: a museum perspective. In Proc. of 3rd Int. Conf. on Computer-Human Interaction Research and Applications, 66-77. INSTICC ScitePress (2019).

55. Winter, M., Brunswick, I., Williams, D.: Quantifying the Attention Potential of Pervasive Display Placements. In Proc. of 2nd Int. Conf. on Computer-Human Interaction Research and Applications - Volume 1: CHIRA, 70-80. ISBN 978-989-758-328-5, ISSN 2184-3244, DOI: $10.5220 / 0007223800700080$. (2018)

56. Winter, M., Gorman, M.J., Brunswick, I., Browne, D., Williams, D., Kidney, F.: Fail Better: Lessons Learned from a Formative Evaluation of Social Object Labels. In Proc. of 8th Int. Workshop on Personalized Access to Cultural Heritage, 1-9. CEUR Workshop Proceedings (2015). 